\title{
CES
}

COOPERATIVISMO E ECONOMÍA SOCIAL

Núm. 41 (2018-2019), páxs. 283-291

ISSN: $1130-2682$

\section{EXTREMADURA APRUEBA UNA NUEVA \\ LEY DE COOPERATIVAS}

EXTREMADURA APPROVES A NEW LAW OF COOPERATIVES

M. a Jesús RodríGuez MíGUEZ*

\footnotetext{
* Abogada del ICA de Pontevedra. Dirección de correo electrónico: mjrmiguez@ mundo-r.com.
} 


\title{
RESUMEN
}

La Comunidad Autónoma de Extremadura aprueba una nueva Ley de Cooperativas, la Ley $9 / 2018$, de 30 de octubre, de sociedades cooperativas de Extremadura (BOE núm. 289, del viernes 30 de noviembre de 2018) con la que reemplaza su Ley 2/1998, de 26 de marzo, de Sociedades Cooperativas de Extremadura.

El nuevo cuerpo legal incorpora diversos cambios entre los que destacan los relativos a la participación de las mujeres, el voto según el capital social o la creación de la clase de las cooperativas juveniles.

Palabras Clave: Economía Social, Sociedades cooperativas, Economía Social.

\begin{abstract}
The Autonomous Community of Extremadura approves a new Law on Cooperatives, the Law 9/2018, of October 30, of cooperative societies of Extremadura (BOE No. 289, of Friday, November 30, 2018) with which it replaces its Law 2 / 1998, of March 26, of Societies Cooperatives of Extremadura.

The new legal body incorporates several changes among which are those related to the participation of women, the vote according to social capital or the creation of the class of youth cooperatives.
\end{abstract}

KeYwords: Social Economy, Cooperative societies, Social Economy. 
SUMARIO: 1. PRESENTACIÓN. 2. ESTRUCTURA. 3. NOVEDADES MÁS SIGNIFICATIVOS INTRODUCIDOS EN LA REGULACIÓN DE LAS COOPERATIVAS EN EXTREMADURA. 3.1. Participación de las mujeres. 3.2. El voto según el capital social. 3.3. Cooperativas juveniles. 3.4. Otras novedades: la cuestión de los llamados "falsos autónomos". 4. VALORACIÓN FINAL.

CONTENTS: 1. PRESENTATION. 2. STRUCTURE. 3. MOST SIGNIFICANT INNOVATIONS INTRODUCED IN THE REGULATION OF COOPERATIVES IN EXTREMADURA. 3.1. Participation of women. 3.2. The vote according to the social capital. 3.3. Youth Cooperatives. 3.4. Other news: the question of the so-called "false self-employed". 4. FINAL ASSESSMENT.

\section{Presentación}

omo expresamos en el título de esta Crónica, Extremadura aprueba una nueva Ley de Cooperativas, con la que reemplaza su Ley 2/1998, de 26 de marzo, de sociedades cooperativas de Extremadura, por la nueva Ley 9/2018, de 30 de octubre, de sociedades cooperativas de Extremadura (BOE núm. 289, del viernes 30 de noviembre de 2018).

Llama la atención - y es honesto destacarlo con carácter preliminar-, que no encontramos justificación explícita en la nueva norma a la adopción de un texto legal completo frente a la opción de la modificación del texto hasta entonces vigente, que ya había sido objeto de varias reformas. Personalmente consideramos que esta última opción permite visualizar mejor los cambios realmente introducidos, que podría complementarse, en su caso, con la ulterior publicación de una versión consolidada. No cabe duda de que la simplificación normativa implica también, a nuestro juicio, mantener la identidad y estructura, cuando sea posible, de las leyes y normas vigentes, pues ello facilita su mejor conocimiento y aplicación.

\section{ESTRUCTURA}

La nueva Ley 9/2018, de 30 de octubre, consta además de una Exposición de Motivos (EM) y un total de 197 artículos (frente a los 186, de la Ley 2/1998, de 26 de marzo, de sociedades cooperativas de Extremadura), estructurados en 4 títulos, más las correspondientes disposiciones adicionales (9), transitorias (4), derogatoria única y Disposiciones finales (4). Se trata pues, de un texto algo más extenso que el anterior, cuyo contenido se expone en 4 títulos, frente a los 3 de la norma anterior. y que contaba con un título menos $\left(3 / 4^{1}\right)$.

1 Cfr Ley 2/1998: Titulo I. De la sociedad cooperativa; Titulo II. De la Administración Pública y las sociedades cooperativas y Titulo III. Del asociacionismo y promoción de las sociedades cooperativas 


\section{NOVEDADES MÁS SIGNIFICATIVOS INTRODUCIDOS EN LA REGULACIÓN DE LAS COOPERATIVAS EN EXTREMADURA}

Como es obvio, la nueva ley introduce cambios en la regulación que hasta entonces estaba vigente en Extremadura, esto es, respecto de "[...] las sociedades cooperativas con domicilio social en el territorio de la Comunidad Autónoma de Extremadura, que desarrollen con carácter principal su actividad cooperativizada en dicho territorio, sin perjuicio de las actividades que realicen con terceros no socios, así como de cualesquiera otras de naturaleza instrumental, accesoria o complementaria que pudieran ser llevadas a cabo incluso fuera de dicho territorio.” (Artículo 2. Ámbito de aplicación. Apartado $1^{\circ}$ ).

La nueva norma parte, en consecuencia, de la anterior, introduciendo algunas modificaciones ${ }^{2}$ que merecen un breve comentario que comienza por la referencia al proceso de su tramitación antes la cámara parlamentaria autonómica. Así, se destaca que el proyecto de ley no tuvo enmienda de totalidad por parte de ningún grupo político, pero sí 148 enmiendas parciales (74 de Podemos, 45 del PP, 16 de Ciudadanos y 13 del PSOE), de las cuales, una parte importante de ellas se han aprobado y, en consecuencia, quedan incorporadas a la nueva Ley. De estas enmiendas, las de Podemos se centraban en aspectos más sustantivos, mientras las del resto de grupos parlamentarios fundamentalmente abordaban cuestiones de pequeña mejora técnica o gramatical.

Veamos brevemente los cambios más importantes, pues dada la extensión del texto y la naturaleza de crónica de este comentario, no parece posible un examen exhaustivo de la norma. Debemos advertir, no obstante, al hilo de lo ya expuesto, que la Exposición de Motivos (EM), no ofrece en esta ocasión grandes pistas sobre dichas novedades Quien lea dicha EM creerá, hasta leer la disposición derogatoria, que Extremadura no tenía legislación propia al respecto lo cual, aun aprobándose una nueva ley, parece tal vez, inapropiado pues puede suscitar confusión.

Nos limitaremos, pues a descara sus aspectos más significativos. A este respecto, los comentarios ya existentes sobre el mismo han subrayado tres aspectos principales: La participación de las mujeres, el voto según el capital social y las cooperativas juveniles. Nos centraremos en estos tres aspectos - no exentos de polémica- $\mathrm{y}$ aludiremos brevemente algunas otras novedades.

Frente a los 4 de la actual Ley 9/2018: Título I. La sociedad cooperativa; Título II. Clases de sociedades cooperativas; Título III. Administración Pública y sociedades cooperativas y Título IV. Asociacionismo cooperativo.

2 Como tendremos ocasión de señalar, algunas de las novedades incorporadas a la regulación autonómica no ha estado exenta de polémica. 


\subsection{Participación de las mujeres}

No cabe duda que las cuestiones relativas a la igualdad de género tienen cada vez mayor importancia y a esta necesidad trata de responder la nueva ley en el ámbito específico de las cooperativas, por tratarse de una cuestión no abordada con anterioridad, como puso de relieve el informe del Instituto de la Mujer de Extremadura. Así, por ejemplo, se recogía que en Extremadura la asistencia a la asamblea general de las cooperativas y la participación en ellas de las mujeres está por debajo del 20\%, y cuando asisten, apenas se atreven a hablar y tomar decisiones, y en los consejos rectores apenas supera el $4 \%$ las mujeres que lo integran. La situación es aún más alarmante respecto a determinados sectores, así por ejemplo en las cooperativas agroganaderas. De las 242 existentes en Extremadura, solo en dos de ellas hay una presidenta el frente."

Para intentar cambiar progresivamente esta situación se ha introducido en la Ley medidas como la prohibición de recibir subvenciones a las cooperativas cuyo consejo rector no tenga al menos un número de integrantes mujeres proporcional al número de socias de la cooperativa. Así, el Artículo 50, relativo a la composición del Consejo Rector, dispone en su apartado $7^{\circ}$ :

“7. La sociedad cooperativa asegurará la representatividad de todos sus socios y socias. Para ello, el consejo rector, en su composición, tenderá a la paridad y habrá, al menos, un número de integrantes mujeres proporcional al número de socias que tenga la sociedad cooperativa.

El incumplimiento de esta obligación conllevará la prohibición a la sociedad cooperativa de obtener la condición de beneficiaria de las subvenciones cuyas bases reguladoras y convocatorias sean aprobadas por la Administración de la Comunidad Autónoma de Extremadura.

Si no se alcanzase la paridad, en la memoria de cuentas anuales de la sociedad cooperativa se deberá justificar, debidamente, el motivo y el procedimiento a seguir para alcanzarla. Además, el incumplimiento de la proporcionalidad respecto al número de socias que tenga la cooperativa supondrá la comisión de una infracción leve de las tipificadas en el artículo 185.3 de esta Ley."

En la misma línea se sitúa la obligación de constituir, en las cooperativas que cuenten con un número de socios comunes igual o superior a 50 o en las de menos cuando lo acuerde su asamblea general, un "Comité de Igualdad" (Artículo 64. Comité de igualdad) o las destinadas a favorecer la asistencia y participación de las socias a las asambleas generales, garantizar también la paridad en los administradores de la cooperativa las comisiones ejecutivas o delegadas y en el comité de recursos (Artículos 50.7, ya aludido y 56.1, entre otros). 


\subsection{El voto según el capital social}

Esta previsión, tan común a las sociedades mercantiles en general es probablemente una de las que más polémica ha suscitado en la nueva normativa extremeña. En efecto, en la anterior Ley, que seguía el modelo tradicional de las cooperativas, cada socio o socia integrante de las cooperativas tenía un voto, con independencia del capital social que hubiere suscrito y desembolsado, a excepción, por sus características especiales, de las cooperativas agrarias. Se trataba, como es bien sabido, de una manifestación del tradicional principio de "un socio, un voto", que es lo que ha venido siendo uno de los rasgos configuradores tradicionalmente asociados a las sociedades cooperativas, dada su pertenecía a la denominada, Economía Social marcándose así la diferencia entre éstas y las sociedades mercantiles convencionales, consagrándose así el denominado "principio de gestión democrática y asamblearia"al primar dicha igualdad entre los socios frente a su participación en el capital social. Por esta razón, dicho principio sigue siendo el mantenido tanto por la legislación estatal, como por numerosas autonómicas en materia de cooperativas. La ruptura, como veremos, con este principio ha sido uno de los aspectos más destacados de la nueva regulación extremeña.

Esta cuestión es abordada, con carácter preliminar, en la EM. Así, en ella se pueden leer las siguientes afirmaciones ${ }^{3}$ :

"Debe destacarse la preferencia de la Ley por el sistema de voto plural. La admisión del voto plural es una constante en el Derecho positivo, tanto histórico como vigente, tanto español como comunitario y comparado. Y es que el voto plural tiene fundamento en la mutualidad, es decir, en la actividad cooperativizada que realiza el socio para satisfacer sus necesidades. El socio de la sociedad cooperativa además de aportar capital desarrolla actividades económicas con la sociedad cooperativa, de tal manera que el patrimonio de aquel puede verse afectado por dos vías —el valor de su aportación al capital social y los resultados positivos o negativos de la actividad cooperativizada-, por lo que es lícito decir, sin quebranto de la ortodoxia cooperativa, que en las situaciones de mayor actividad cooperativizada debe reconocerse más poder de decisión, mayor nivel de voto, lo que debe traducirse en un sistema de voto plural proporcional a la actividad cooperativizada. Sin embargo, es difícil romper con la inercia histórica y acoger de pleno las exigencias derivadas de la mutualidad, por ello, la Ley regula un sistema de voto plural, pero permite que los estatutos prevean el voto unitario. En cambio, para las sociedades cooperativas de trabajo asociado donde la mutualidad se mide principalmente por la persona, más que por su ac-

\footnotetext{
Epígrafe VI de la EM.
} 
tividad, el sistema legal es el inverso: el voto unitario, salvo que los estatutos prevean el plural."

Esta afirmación de la EM unida al texto de los preceptos que anticipa nos hace cuestionar la crítica dirigida al texto final, de que prima el capital social, -lo que aproximaría aun más a las cooperativas a las demás sociedades mercantiles-, sino que trata de ajustar el peso del voto a la "actividad cooperativizada", concepto que no entendemos, tras leer los texto positivos indicados, únicamente ligado a las aportaciones al capital social.

\subsection{Cooperativas juveniles}

La nueva ley dedica el Capítulo XVI, del extenso Título I ("La sociedad cooperativa"), a la regulación de las "Sociedades cooperativas juveniles", compuesto por un único precepto, el Artículo 174, en el que expone su "Objeto y régimen jurídico".

Este nuevo tipo de sociedad cooperativa, introducido mediante enmienda durante la tramitación del proyecto de ley, identifica, conforme a lo dispuesto en el apartado 1 del citado precepto (Artículo 174), a las sociedades cooperativas que tienen por objeto "proporcionar empleo y un marco apropiado para el desarrollo profesional a la juventud, mediante la prestación de su trabajo personal produciendo en común bienes y servicios para terceros", añadiendo en un segundo párrafo que deberán estar formadas "mayoritariamente por personas socias trabajadoras con edades comprendidas entre los dieciséis y treinta años, salvo en caso de que sean personas con un grado de discapacidad igual o superior al $33 \%$, en el cual la edad máxima será de treinta y cinco años". Se trata pues, de una fórmula, como se ha destacado "dirigida a dar facilidades al autoempleo a un colectivo duramente castigado por el desempleo y la precariedad". ${ }^{4}$

\subsection{Otras novedades: la cuestión de los llamados "falsos autónomos"}

Una de las novedades más sobresalientes de la nueva ley tiene como finalidad la lucha contra lo que se ha denominado "falsos autónomos" y que es una cuestión de gran importancia y, sin duda, de gran actualidad, especialmente respecto de los nuevos modelos de negocio surgidos con la aparición de plataformas digitales ${ }^{5}$.

Las dudas y problemas que suscita la figura de los "falsos autónomos" se plantean también en el mundo cooperativo. De ahí la importancia de la incorporación

\footnotetext{
${ }^{4}$ Cfr. "La nueva Ley de Cooperativas de Extremadura rompe con el principio democrático", disponible en https://www.elsaltodiario.com/saltamos-extremadura/nueva-ley-cooperativas-extremadura-rompeprincipio-democratico

5 Cfr., principalmente los Artículos 146 y 147) de la nueva ley.
} 
de esta cuestión en la nueva ley. Baste apunta que es uno de los temas que se tratan en el Acuerdo del Consejo de Ministros de 27 de julio de 2018, por el que se aprueba el Plan Director por un Trabajo Digno 2018-2019-2020. A este respecto 6 .

En dicho Acuerdo, entre las medidas Operativas, concretamente el número 5 Refuerzo de la lucha contra la economía irregular, en las medidas relativas al refuerzo de la Inspección de Trabajo se puede leer lo siguientes (extracto):

"B) Se ha denominado como trabajo declarado incompleto aquellos en los que existen una infra cotización a la Seguridad Social o un encuadramiento indebido dentro del Sistema con la finalidad de obtener un ahorro en los gastos sociales. El principal exponente de este fenómeno son los denominados «falsos autónomos», provocado porque ciertos empresarios, en su deseo de mejorar de una manera fácil su competitividad, han recurrido a esta figura para reducir fraudulentamente los costes laborales, evitando la cotización por ellos al Régimen General de la Seguridad Social y solicitando el trabajador el alta en el Régimen Especial de la Seguridad Social de Trabajadores Autónomos asumiendo éste, por tanto, la totalidad de la cotización a la Seguridad Social. Todo ello supone una lesión a los derechos de los trabajadores y trabajadoras afectados, siendo un claro ejemplo de precarización de las relaciones laborales al desproveer a estos trabajadores de protección social, implicando igualmente competencia desleal para las empresas que cumplen con sus obligaciones legales, y un fraude a la Seguridad Social, al eludir la cotización correspondiente.

Si bien en determinados supuestos, la Inspección de Trabajo ha detectado que determinadas empresas han instado a trabajadores a renunciar a su inclusión en el Régimen General de la Seguridad Social, para así justificar la inexistencia de relación laboral a pesar de la falta de autonomía y de las múltiples notas de ajeneidad de la misma, hay que reafirmar que el régimen de seguridad social es indisponible y vendrá determinado por la verdadera naturaleza jurídica de la prestación de servicios que realizan.

Relacionado directamente con la figura del falso autónomo, se han detectado ciertos comportamiento consistentes en la «utilización« de

\footnotetext{
${ }^{6}$ Cfr. Resolución de 27 de julio de 2018, de la Subsecretaría, por la que se publica el Acuerdo del Consejo de Ministros de 27 de julio de 2018, por el que se aprueba el Plan Director por un Trabajo Digno 2018-2019-2020 (BOE n 182 Sábado 28 de julio de 2018). Para más información acerca de esta figura y los problemas que suscita, vid. Descentralización productiva, nuevas formas de trabajo y organización empresarial: XXVIII Congreso de Derecho del Trabajo y de la Seguridad Social, Santiago de Compostela, 31 de mayo y 1 de junio de 2018 / coord. por Asociación Española de Derecho del Trabajo y de la Seguridad Social, Vol. 2, 2018 (CD), ISBN 9788416668557. Mas información en https://dialnet.unirioja.es/servlet/libro?codigo=713469
} 
forma fraudulenta de las distintas formas de organización social (cooperativas) para aprovecharse del legítimo derecho de opción que la normativa concede a las mismas, en cuanto al régimen de seguridad social aplicable, especialmente en las cooperativas de trabajo asociado, sirviendo estas para enmascarar verdaderas relaciones laborales con la mercantil que utiliza las citadas cooperativas, dado que no existe una autentica relación societaria. El objetivo de este comportamiento es no asumir las obligaciones y responsabilidades que la ley les atribuye como empleador, con los efectos tan devastadores que provoca en las personas que emplea, ya que carecen de derechos laborales, así como de determinada protección social. Estas prácticas fraudulentas no se corresponden con el comportamiento mayoritario de las sociedades cooperativas.

$[\ldots] "$

El nuevo marco legal, se ha destacado también por sus esfuerzos para moderniza y mejora los derechos de información y transparencia en la gestión de la cooperativa, puesto que, entre otras opciones, podrán tener una página web corporativa para cumplir con la publicidad de los actos, acuerdos y documentos y posibilitar la comunicación de los socios con la sociedad, que podrá realizarse también por medios electrónicos. Se trata, de una realidad impuesta por lo tiempos y a la que muchas cooperativas habían llegado ya respondiendo a sus propias necesidades en los mercados en los que la digitalización constituye ya un capítulo inexcusable.

\section{VALORACIÓN FINAL}

Parece evidente que el nuevo marco legal de las cooperativas extremeñas ofrece una guía renovada de su estructura y reglas de juego, que esperamos potencie su desarrollo. 